\title{
Cardiac safety in cluster headache patients using the very high dose of verapamil $(\geq 720 \mathrm{mg} /$ day)
}

\author{
M. Lanteri-Minet $\cdot$ F. Silhol $\cdot$ V. Piano • \\ A. Donnet
}

Received: 3 September 2010/ Accepted: 29 December 2010/Published online: 22 January 2011

(C) The Author(s) 2011. This article is published with open access at Springerlink.com

\begin{abstract}
Use of high doses of verapamil in preventive treatment of cluster headache $(\mathrm{CH})$ is limited by cardiac toxicity. We systematically assess the cardiac safety of the very high dose of verapamil (verapamil VHD) in $\mathrm{CH}$ patients. Our work was a study performed in two French headache centers (Marseilles-Nice) from 12/2005 to $12 / 2008$. CH patients treated with verapamil VHD $(\geq 720 \mathrm{mg}$ ) were considered with a systematic electrocardiogram (EKG) monitoring. Among $200 \mathrm{CH}$ patients, 29 $(14.8 \%)$ used verapamil VHD $(877 \pm 227 \mathrm{mg} /$ day $)$. Incidence of EKG changes was $38 \%$ (11/29). Seven (24\%) patients presented bradycardia considered as nonserious adverse event (NSAE) and four (14\%) patients presented arrhythmia (heart block) considered as serious adverse event (SAE). Patients with EKG changes $(1,003 \pm 295 \mathrm{mg} /$ day $)$ were taking higher doses than those without EKG changes ( $800 \pm 143 \mathrm{mg} /$ day), but doses were similar in patients with $\operatorname{SAE}(990 \pm 316 \mathrm{mg} /$ day $)$ and those with NSAE $(1,011 \pm 309 \mathrm{mg} /$ day $)$. Around three-quarters $(8 / 11)$ of
\end{abstract}

M. Lanteri-Minet $(\bowtie) \cdot$ V. Piano

Département d'Evaluation et traitement de la Douleur Médecine palliative, Pôle Neurosciences Cliniques du CHU de Nice, Hôpital Pasteur Avenue de la Voie Romaine, 06002 Nice Cedex, France

e-mail: lanteri-minet.m@chu-nice.fr

M. Lanteri-Minet

INSERM Unité 829, Faculté de Chirurgie dentaire,

Clermont-Ferrand, France

F. Silhol

Service de Cardiologie, CHU Timone, Rue St Pierre, 13005 Marseille, France

A. Donnet

Service de Neurologie, Pôle Neurosciences cliniques, CHU Timone, Rue St Pierre, 13005 Marseille, France patients presented a delayed-onset cardiac adverse event (delay $\geq 2$ years). Our work confirms the need for systematic EKG monitoring in $\mathrm{CH}$ patients treated with verapamil. Such cardiac safety assessment must be continued even for patients using VHD without any adverse event for a long time.

Keywords Cluster headache · Verapamil · Adverse events $\cdot$ EKG monitoring

\section{Introduction}

According to quality criteria developed by the American Academy of Neurology [1], verapamil received a grade C rating in a recent meta-analysis of trials of pharmacotherapy for cluster headache $(\mathrm{CH})$ [2]. In spite of this low evidence level, verapamil is generally considered to be the mainstay of $\mathrm{CH}$ preventive therapy as in the European guidelines [3]. The starting daily dose of verapamil in $\mathrm{CH}$ should be the $360 \mathrm{mg}$ effective in two randomized clinical trials [4, 5]. The daily dose could be increased up to $720 \mathrm{mg}$ and some $\mathrm{CH}$ patients may even need unusual very high daily dose from 720 to $1,200 \mathrm{mg}$ [6]. Considering such a clinical practice, the dose of verapamil used for $\mathrm{CH}$ is approximately twice the dose required by cardiovascular diseases [7]. This difference could be explained by the fact that the cardiovascular effects are related to blood level, whereas the preventive $\mathrm{CH}$ effect takes place across the blood-brain barrier where the efflux transporter P-glycoprotein restricts net brain uptake of verapamil by immediately transporting it out of the brain [8]. Considering the use of high doses, the cardiac safety of verapamil therapy was specifically studied in one series that included $108 \mathrm{CH}$ patients treated by verapamil with systematic electrocardiogram (EKG) 
assessment [9]. In this series, verapamil was started at $240 \mathrm{mg} /$ day and then increased until the $\mathrm{CH}$ was suppressed, or to a maximum daily dose of $960 \mathrm{mg}$ (mean daily dose $584 \pm 257 \mathrm{mg}$ ) and incidence of arrhythmia was $19 \%$ and bradycardia 36\% [9]. We developed a similar approach to assess the cardiac safety of verapamil therapy in $\mathrm{CH}$ with a focus on very high daily dose equal or higher than $720 \mathrm{mg} /$ day.

\section{Methods}

The notes were assessed for patients with episodic $\mathrm{CH}$ or chronic $\mathrm{CH}$ attending two headache specialty centers (Marseilles and Nice) belonging to the French Observatory of Migraine and Headaches [10] from December 2005 to December 2008. Patients had a diagnosis of $\mathrm{CH}$ according to the criteria of the second edition of the International Classification of Headache Disorders [11]. When the verapamil was used, the starting dose was $360 \mathrm{mg}$ with an increase by $120 \mathrm{mg}$ every 2 weeks with a check EKG, until the $\mathrm{CH}$ was suppressed or adverse events intervened. Ordinary release formulation or controlled release formulation were both used.

Study considered $\mathrm{CH}$ patients using verapamil with a very high daily dose defined as $\geq 720 \mathrm{mg}$. The following data were collected for each patient: sex, age, tobacco use and cardiovascular history, diagnosis (episodic or chronic $\mathrm{CH}$ ), duration of verapamil use, very high dose of verapamil achieved, duration of use of such a very high dose of verapamil, concomitant medications, clinical adverse events related to verapamil (constipation, lethargy, hypotension, lower edema, dyspnea, impotence, gingival hyperplasia). EKG assessment before verapamil introduction was compared with EKG assessment done at the very high dose of verapamil achieved.

\section{Results}

Patients

Among $200 \mathrm{CH}$ identified seen during the study period, 29 (14.8\%) used verapamil with a daily dose $\geq 720 \mathrm{mg}$. Very high verapamil dose $\mathrm{CH}$ patients were 28 men and 1 woman with a mean age $43.2 \pm 10$ years (range 21-55 years). Twenty one were present smokers, six were past smokers and two had never smoked. Three had a high blood pressure and one a coronary heart disease. Nine suffered of episodic $\mathrm{CH}$ and 20 of chronic $\mathrm{CH}$. Mean duration of verapamil therapy was $46 \pm 36$ months and mean duration of very high dose use was $36 \pm 32$ months. Mean very high dose of verapamil was $877 \pm 227 \mathrm{mg} /$ day
(720 mg: 16; $840 \mathrm{mg}:$ 2; $960 \mathrm{mg}:$ 7; 1,200 mg: 1; 1,440 mg: 3). Concomitant treatments for $\mathrm{CH}$ (acute and prophylactic) are presented in Table 1.

\section{EKG changes}

EKG changes concerned 11 (38\%) patients: bradycardia (heart rate $<60 \mathrm{bpm}$ ) in 7 patients, first-degree heart block (PR interval $>0.2 \mathrm{~s}$ ) in 2 patients, second-degree heart block in 1 patient and third degree heart block in 1 patient. Patients with EKG changes used a mean verapamil daily dose of $1,003 \pm 295 \mathrm{mg}$, whereas patients without EKG changes used a mean verapamil dose of $800 \pm 143 \mathrm{mg}$. EKG changes have been considered as cardiac serious adverse event (SAE) in the four (14\%) patients with heart block inducing verapamil discontinuation in two patients and a dose reduction in one patient. EKG changes have been considered as cardiac nonserious adverse event (NSAE) in seven (24\%) patients with bradycardia, but verapamil dose was decreased in one patient.

Cardiac SAE concerned 4 men with mean age $40.2 \pm 14.5$ years (range 21-52 years) and using a mean very high verapamil daily dose of $990 \pm 315 \mathrm{mg}$. One patient had a high blood pressure history and regarding tobacco use, two were present smokers, one was past smoker and one patient had never smoked. Cardiac SAE concerned patients using verapamil without concomitant medications expect sumatriptan or zolmitriptan as acute treatment. Cardiac SAE were delayed onset in three patients $(72,71$ and 24 months after the very high dose was achieved). Cardiac SAE were asymptomatic in two patients and symptomatic in two patients with lethargy, and dyspnea for one patient and lethargy for the other.

Cardiac NSAE concerned seven men with mean age $40.7 \pm 10$ years (range 28-52 years) and using a mean very high verapamil daily dose of $1,011 \pm 309 \mathrm{mg}$. No patient had cardiovascular history and regarding tobacco use, six were present smokers and one had never smoked. Cardiac NSAE concerned one patient without any concomitant treatment, three patients without concomitant treatment except acute treatment (sumatriptan and oxygen) and three patients with prophylactic concomitant treatment (topiramate and/or indomethacin). Cardiac NSAE was delayed onset in five patients $(60,36,27,24$ and 24 months after the very high dose was achieved). Cardiac NSAE were asympomatic in four patients and associated lethargy in the three other patients.

\section{Discussion}

Considering the frequent use of high daily doses, cardiac safety assessment with systematic EKG monitoring is 
Table 1 Cardiac safety of the very high verapamil $\mathrm{CH}$ patients

\begin{tabular}{|c|c|c|c|c|c|c|c|c|c|c|c|c|c|c|}
\hline & Sex & Age & $\mathrm{TU}$ & $\mathrm{CVH}$ & $\mathrm{CH}$ & vD & vSMD & SM & ACT & PCT & EKG changes & SAE & $\mathrm{vC}$ & CAE \\
\hline 1 & M & 50 & Present & No & $\mathrm{C}$ & 108 & 96 & 1,200 & $\mathrm{scS}$ & No & No & & & No \\
\hline 2 & $\mathbf{M}$ & 21 & No & No & $\mathbf{E}$ & 84 & 72 & 960 & $\operatorname{scS}$ & No & Second degree $\mathrm{HB}$ & Yes & Stop & No \\
\hline 3 & $M$ & 45 & Present & No & $E$ & 12 & 2 & 960 & $s c S$ & No & Bradycardia & No & No & No \\
\hline 4 & $M$ & 47 & Present & No & $C$ & 72 & 60 & 840 & $s c S$ & $T$ & Bradycardia & No & No & No \\
\hline 5 & M & 55 & Past & HBP & $\mathrm{E}$ & 1 & 1 & 720 & $\mathrm{scS}$ & No & No & & & $\mathrm{D}$ \\
\hline 6 & M & 34 & Present & No & $\mathrm{C}$ & 12 & 1 & 720 & $\mathrm{scS}$ & No & No & & & No \\
\hline 7 & $M$ & 50 & Present & No & $C$ & 36 & 24 & 1,440 & $s c C$ & No & Bradycardia & No & No & $L$ \\
\hline 8 & M & 33 & Present & No & $\mathrm{E}$ & 48 & 1 & 720 & $\mathrm{scC}$ & No & No & & & No \\
\hline 9 & M & 46 & Past & No & $\mathrm{E}$ & 1 & 1 & 720 & $\mathrm{scC}$ & No & No & & & $\mathrm{L}$ \\
\hline 10 & M & 37 & Present & No & $\mathrm{E}$ & 1 & 1 & 720 & $\mathrm{scC}$ & No & No & & & $\mathrm{C}$ \\
\hline 11 & M & 72 & Present & No & $\mathrm{E}$ & 3 & 2.5 & 960 & $\mathrm{O}_{2}$ & No & No & & & $\mathrm{C}$ \\
\hline 12 & M & 51 & Past & No & $\mathbf{C}$ & 36 & 24 & 1,440 & $\mathbf{o Z}$ & No & Third degree HB & Yes & Stop & L-D \\
\hline 13 & M & 49 & Present & No & $\mathrm{C}$ & 120 & 96 & 960 & $\mathrm{scC}$ & $\mathrm{L}$ & No & & & No \\
\hline 14 & M & 52 & Present & No & $\mathbf{E}$ & 1 & 1 & 840 & scC & No & First HB & Yes & $\downarrow 600$ & D-E \\
\hline 15 & $M$ & 30 & No & No & $E$ & 1 & 1 & 960 & No & No & Bradycardia & No & No & No \\
\hline 16 & $M$ & 33 & Present & No & $C$ & 25 & 24 & 720 & $s c S$ & $T-I$ & Bradycardia & No & No & $L$ \\
\hline 17 & M & 37 & Present & HBP & $\mathbf{C}$ & 72 & 71 & 720 & scC & $\mathbf{G}$ & First HB & Yes & $\downarrow 840$ & No \\
\hline 18 & M & 40 & Present & No & $\mathrm{C}$ & 47 & 46 & 960 & $\mathrm{scC}$ & No & No & & & L-E \\
\hline 19 & M & 53 & Past & HBP & $\mathrm{C}$ & 96 & 93 & 720 & $\mathrm{scC}$ & No & No & & & L-D-I \\
\hline 20 & M & 37 & Present & No & $\mathrm{C}$ & 76 & 53 & 720 & $\mathrm{scC}-\mathrm{O}_{2}$ & No & No & & & L-D-E \\
\hline 21 & M & 42 & Present & No & $\mathrm{C}$ & 17 & 10 & 720 & $\mathrm{scC}$ & I & No & & & L-E-G \\
\hline 22 & W & 34 & Past & No & $\mathrm{C}$ & 18 & 10 & 720 & $\mathrm{scC}-\mathrm{O}_{2}$ & No & No & & & $\mathrm{L}$ \\
\hline 23 & M & 55 & Present & No & $\mathrm{C}$ & 53 & 51 & 720 & $\mathrm{scC}$ & No & No & & & $\mathrm{L}$ \\
\hline 24 & $\mathrm{M}$ & 41 & Present & No & $\mathrm{C}$ & 84 & 58 & 960 & $\mathrm{scC}$ & No & No & & & L-D-E \\
\hline 25 & $M$ & 28 & Present & No & $C$ & 37 & 36 & 720 & $s c C-O_{2}$ & No & Bradycardia & No & No & $L$ \\
\hline 26 & M & 31 & Present & No & $\mathrm{C}$ & 81 & 46 & 720 & $\mathrm{scC}$ & I & No & & & No \\
\hline 27 & $M$ & 52 & Present & No & $C$ & 27 & 24 & 1,440 & $s c C$ & $I$ & Bradycardia & No & $\downarrow 1,200$ & No \\
\hline 28 & $\mathrm{H}$ & 54 & Past & CAD & $\mathrm{C}$ & 71 & 53 & 720 & $\mathrm{scC}$ & No & No & & & No \\
\hline 29 & $\mathrm{H}$ & 33 & Present & No & $\mathrm{C}$ & 96 & 85 & 720 & $\mathrm{scC}$ & No & No & & & $\mathrm{L}$ \\
\hline
\end{tabular}

Sex, age (years), tobacco use (TU), cardiovascular history (CVH) with high blood pressure (HBP) and coronary arteries disease (CAD), type of $\mathrm{CH}$ (E: episodic $\mathrm{CH}-\mathrm{C}$ : chronic $\mathrm{CH}$ ), duration of verapamil use (vD) in months, duration of supra-maximum dose of verapamil (vSMD) in months, supra-maximum dose of verapamil achieved (SM) in mg/day, acute concomitant treatments (ACT/scC: subcutaneous sumatriptan-oZ: oral $-\mathrm{O}_{2}$ : oxygen), prophylactic concomitant treatments (PCT/I: indomethacin-G: gabapentin-L: lithium-T: topiramate), electrocardiogram (EKG) changes, serious adverse event (SAE), change in verapamil dose (vC), clinical adverse events (CAE/C: constipation-D: dyspnea-E: edema of lower limbs-G: gingival hyperplasia-I: impotence-L: lethargy)

Patients with serious cardiac adverse event are in bold and patient with nonserious cardiac adverse event are in italics

essential in the management of $\mathrm{CH}$ patients treated by verapamil [7]. This is all the more essential as the very high daily dose $(\geq 720 \mathrm{mg})$ is used. The use of the very high daily dose is not infrequent and our study showed that it corresponds to $14.8 \%$ of $\mathrm{CH}$ patients managed in two centers representative of French headache tertiary centers. In this group patients treated with the very high daily dose of verapamil ( $877 \pm 227 \mathrm{mg}$ ), systematic EKG monitoring demonstrated that incidence of cardiac adverse events is $38 \%$, with more than one-third of cases, the occurrence of an adverse event was considered as serious. Cardiac SAE were arrhythmias induced by reduction of transmission in the atrioventricular node: first-degree heart block in two patients needing daily dose reduction, second- and thirddegree heart block in two others patients needing verapamil discontinuation. In a previous study on $108 \mathrm{CH}$ patients using a mean daily dose of $584 \pm 264 \mathrm{mg}$, incidence of arrhythmia (mostly first-degree heart block and junctional rhythm) was $19 \%$ and bradycardia 36\% [9]. In this study, patients with arrhythmia $(567 \pm 290 \mathrm{mg} /$ day $)$ were not taking higher doses than those without arrhythmia (586 $\pm \mathrm{mg} /$ day) [9]. By contrast, we found that patients with EKG changes $(1,003 \pm 295 \mathrm{mg} /$ day $)$ were taking higher doses than those without EKG changes (800 \pm $143 \mathrm{mg} /$ day), but doses were similar in patients with cardiac SAE $(990 \pm 316 \mathrm{mg} /$ day $)$ and those with cardiac 
NSAE $(1,011 \pm 309 \mathrm{mg} /$ day $)$. In our study, cardiac adverse events were not related to the patients' age, cardiovascular history, $\mathrm{CH}$ type and concomitant drugs used for acute and/or prophylactic treatment of $\mathrm{CH}$. All these data are congruent with those previously reported [9] and could be related to an interindividual variability in the pharmacology of verapamil supported by a genetic component [7]. This hypothesis was developed in the cardiologic field and data collected in the INVEST suggests variability in the large-conductance and voltage-dependant potassium channel beta 1 subunit gene, KCNMB1, is associated with the antihypertensive response to verapamil and also with cardiovascular adverse events in patients having hypertension with coronary arteries disease [12]. Our study also suggests an important intra-individual variability in the risk of cardiac adverse events. Such an intraindividual variability could explain the delayed onset of cardiac adverse events which is probably the more striking data collected in our study. Late-onset arrhythmia was previously described in two $\mathrm{CH}$ patient treated with verapamil [9]. Around three-quarters (8/11) of our patients presented cardiac adverse events with a delayed onset, this proportion being similar to bradycardia (5/7) and arrhythmia (3/4). In all these late-onset adverse events cases, the time between the adverse event occurrence date and that corresponding to the very high daily dose verapamil use was equal or higher than 2 years. This confirms the need of regular and systematic EKG monitoring as EKG abnormalities can develop insidiously with rising subthreshold PR intervals, or suddenly after long time of normal EKGs. This systematic assessment is all the more important than cardiac adverse events can occur without any other clinical adverse event as in four of our eight cases with late-onset cardiac adverse event.

Conflicts of interest The authors report no conflicts of interest.

Open Access This article is distributed under the terms of the Creative Commons Attribution License which permits any use, distribution and reproduction in any medium, provided the original author(s) and source are credited.

\section{References}

1. Edlund W, Gronseth G, So Y, Franklin G (2004) Clinical practice guideline process manual. American Academy of Neurology, St. Paul, pp 1-57

2. Francis GJ, Becker WJ, Pringshiem TM (2010) Acute and preventive pharmacologic treatment of cluster headache. Neurology 75:463-473

3. May A, Leone M, Afra J et al (2006) EFNS guidelines on the treatment of cluster headache and other trigeminal-autonomic cephalalgias. Eur J Neurol 13:1066-1077

4. Bussone G, Leone M, Peccarisi C et al (1990) Double blind comparison of lithium and verapamil in cluster headache prophylaxis. Headache 30:411-417

5. Leone M, D'Amico D, Frediani F, Moschiano F, Grazzi L, Attanasio A (2000) Verapamil in the prophylaxis of episodic cluster headache: a double-blind study versus placebo. Neurology 54:1382-1385

6. Gabai IJ, Speirings ELH (1989) Prophylactic treatment of cluster headache with verapamil. Headache 29:167-168

7. Tflelt-Hansen P, Tfelt-Hansen J (2008) Verapamil for cluster headache. Clinical pharmacology and possible mode of action. Headache 49:117-125

8. Luurtsema G, Molthoff CF, Windhorst AD et al (2003) (R)- and (S) [11C]verapamil as PET-tracers for measuring P-glycioprotein function: in vitro and in vivo evaluation. Nucl Med Biol 30:747-751

9. Cohen AS, Matharu MS, Goadsby PJ (2007) Electrocardiographic abnormalities in patients with cluster headache on verapamil therapy. Neurology 69:668-675

10. Lanteri-Minet M, Autret A, Baudesson G et al (2005) French survey network on headaches and facial pains. In: Olesen J (ed) The classification and diagnosis of headache disorders. Oxford University Press, New York, pp 287-293

11. Headache Classification Subcommittee of the International Headache Society (2004) The international classification of headache disorders, 2nd edn. Cephalalgia 24(Suppl 1):1-160

12. Beitelsheess AL, Gong Y, Wang D et al (2007) KCNMB1 genotype influences response to verapamil SR and adverse outcomes in the International VErapamil SR/Trandolapril Study (INVSET). Pharmacogenetic Genomics 17:719-729 